\title{
ANALISIS NUMERIK DISTRIBUSI TEKANAN \& KECEPATAN ALIRAN UDARA PADA FUSELAGE B737-9 MAX
}

\author{
Tri Susilo*, Bismil Rabeta, Fikry Falah \\ Program Studi Teknik Penerbangan, Fakultas Teknologi Kedirgantaraan, \\ Universitas Dirgantara Marsekal Suryadarma \\ Komplek Bandara Halim Perdanakusuma, Jakarta 13610, Indonesia \\ *Corresponding Author : trisusilo@universitassuryadarma.com
}

\begin{abstract}
Abstrak - Karakteristik aerodinamika dapat diketahui dengan menggunakan metode komputasi yaitu Computational Fluid Dynamics (CFD). Penelitian ini menganalisis distribusi tekanan dan kecepatan aliran udara pada fuselage B737-9 MAX dengan metode Computational Fluid Dynamics (CFD) dengan variasi sudut serang $0^{\circ}, 15^{\circ}, 30^{\circ}$ dan $45^{\circ}$. Hasil yang diperoleh adalah pada sudut serang $0^{\circ}, 15^{\circ}$ perbedaan kecepatan dan tekanan tidak terlalu signifikan atau normal, sedangkan pada sudut serang $30^{\circ}$ dan $45^{\circ}$ perbedaan kecepatan dan tekanan sangat signifikan atau tidak normal karena aliran udara pada sudut tersebut mengalami turbulensi disekitar fuselage.

Kata Kunci : Computational Fluid Dynamics (CFD), kecepatan aliran udara, tekanan, fuselage B737-9 MAX

Abstract - Aerodynamic characteristics can be known by using computational Fluid Dynamics (CFD) methods. This study analyzes the pressure distribution and velocity of air flow on Fuselage B737-9 MAX using the Computational Fluid Dynamics (CFD) method with variations in attack angles of $0^{\circ}, 15^{\circ}, 30^{\circ}$ and $45^{\circ}$. The results obtained are at $0^{\circ}$ attack angle, $15^{\circ}$ the difference in speed and pressure is not too significant or normal, while at the attack angle $30^{\circ}$ and $45^{\circ}$ the difference in speed and pressure is very significant or abnormal because the air flow at that angle experiences turbulence around the fuselage.
\end{abstract}

Keywords: Computational Fluid Dynamics (CFD), air flow velocity, pressure, fuselage B737-9 MAX 


\section{PENDAHULUAN}

Pesawat terbang adalah salah satu jenis alat transportasi udara yang telah berkembang dengan cepat dan modern. Segala aspek diperhitungkan dalam membuat sebuah pesawat terbang mulai dari rancangan, bahan-bahan penyusun, mesin, sayap, sistem, dan lain-lain.

Hal ini sebagai upaya untuk mengedepankan fungsi keselamatan pesawat terbang. Performa suatu pesawat terbang dipengaruhi oleh berbagai aspek, salah satu diantaranya adalah aspek aerodinamika. Suatu terminologi aerodinamika adalah ilmu yang membahas pergerakan udara pada suatu benda (objek) yang melewati udara dengan gaya yang dihasilkannya atau perubahan pada pergerakannya. Lebih luasnya lagi dinamika atau pergerakan udara dan gas-gas lain yang terkandung didalamnya dengan gaya yang terjadi saat pergerakan benda (objek) melewati udara atau benda yang diam pada saat dialiri udara.

Untuk mengetahui karakteristik aerodinamika dapat dilakukan dangan cara pengujian model pesawat terbang melalui Computational Fluid Dynamics (CFD). Pada Computational Fluid Dynamics (CFD) tersebut, kita dapat menguji bagian-bagian struktur pesawat terbang seperti: sayap (wing), badan (fuselage), bidang ekor (tail) dan lainnya. Pada Computational Fluid Dynamics (CFD) ini dapat mengetahui sifatsifat aerodinamika pada pesawat terbang.

Berdasakan latar belakang tersebut diatas, maka dalam penulisan kali ini penulis mencoba menganalisis karakteristik aerodinamika sepanjang permukaan atas dan bawah dari model badan (fuselage) pesawat Boeing 737- MAX 9, dikarenakan pesawat merupakan keluaran terbaru dari pabrikan Boeing.

Pada kesempatan kali akan dilakukan simulasi distribusi tekanan dan kecepatan sepanjang permukaan fuselage Boeing 7379 MAX dengan variasi kecepatan aliran udara dan variasi sudut serang. Untuk melakukan analisi komputasi tersebut diatas penulis menggunakan metode komputasi dengan software Solidwork.

\section{METODE PENELITIAN}

Dalam penelitian ini ada beberapa langkah yang dilakukan untuk mendapatkan hasil analisi distibusi tekanan dan kecepatan. Langkah pertama mencari data spesifikasi pesawat Boeing 7379 MAX setelah itu pembuatan pemodelan dengan software dengan perbedaan sudut serang $0^{\circ}, 15^{\circ}, 30^{\circ}$ dan $45^{\circ}$ lalu melakukan proses flow simulation dengan menggunakan Computational Fluid Dynamic (CFD) setelah hasil dari flow simulation didapat, lanjutkan ke analisis data berdasarkan perbedaan sudut tersebut, dan memberikan kesimpulan dalam bentuk data dan Gambar.

\subsection{Spesifikasi Permodelan}

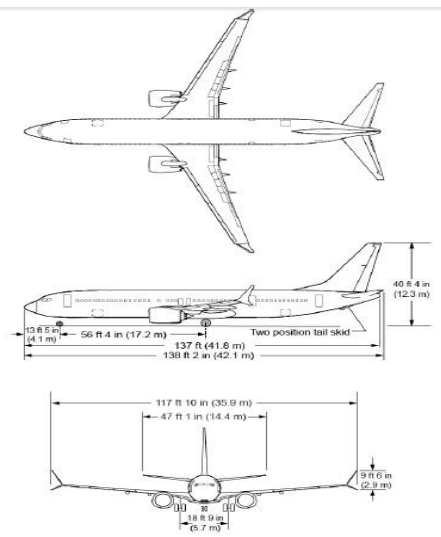

Gambar 2.1 Geometri Fuselage B737-9 Max

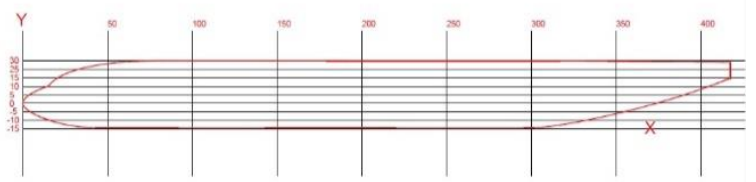

Gambar 2.2 Permodelan Fuselage B737-9 Max

\subsection{Geometry}

Proses permodelan dilakukan dalam beberapa tahap sebagai berikut : 
1. Klik Right Plane lalu edit Sketch.

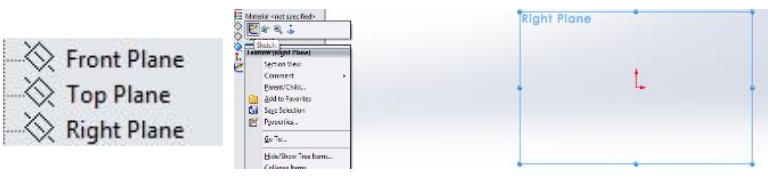

Gambar 2.3 Proses Permodelan Fuselage B737-9 MAX

2. Klik Sketch Tools lalu pilih Skectch Picture.

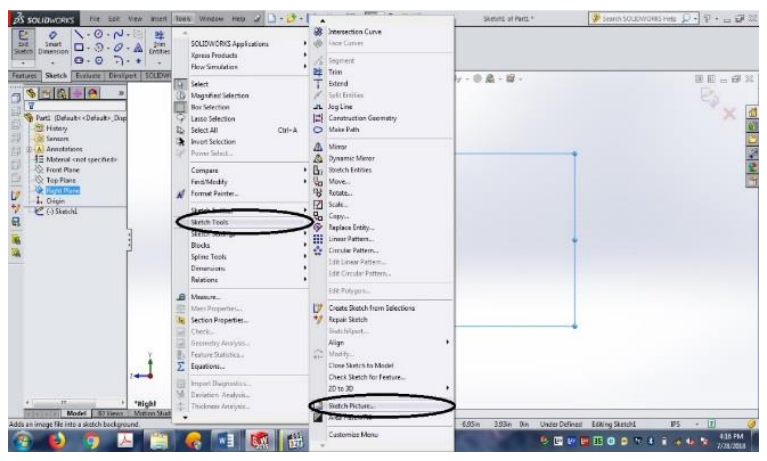

Gambar 2.4 Pembuatan Surface untuk Fuselage B737-9 MAX

3. Pilih Gambar di dokumen sesuai keinginan

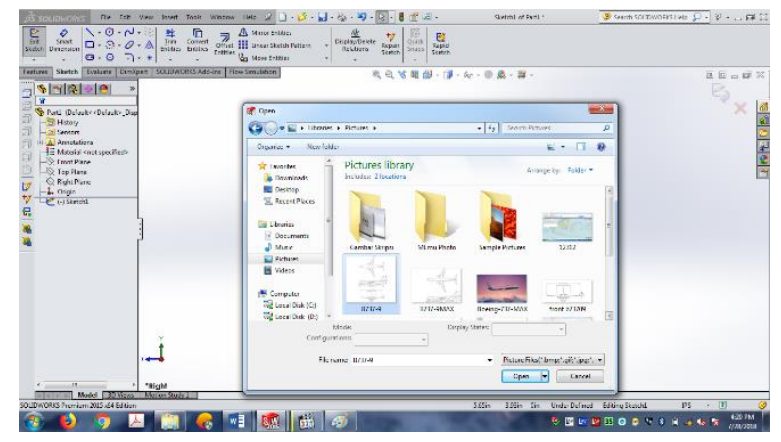

Gambar 2.5 Pemilihan Gambar Sketch

4. Pembuatan Garis Bantu

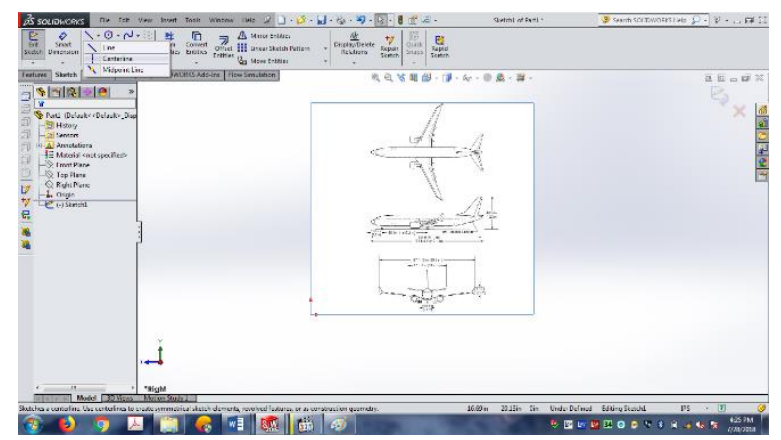

Gambar 2.6 Menggunakan Centerline

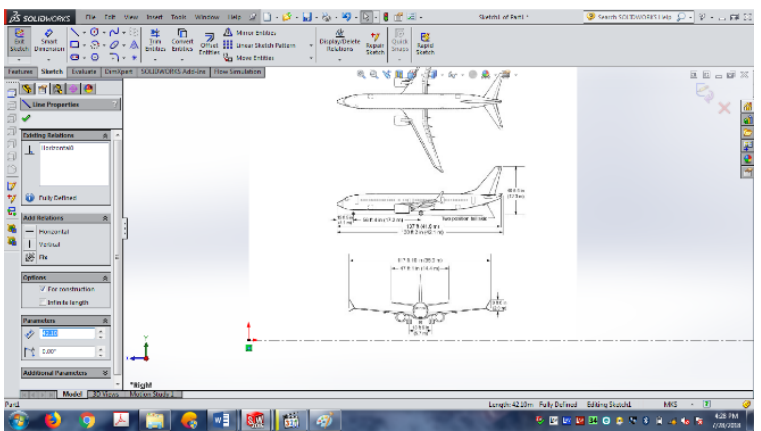

Gambar 2.7 Pemilihan Garis Bantu

Pada proses Gambar 2.6 mengklik command line lalu pilih centerline untuk membuat garis bantu, setelah itu pada Gambar 2.7 memasukan ukuran yang sudah disesuaikan dari Gambar sketch.

5. Pembuatan model 2D untuk tampak samping

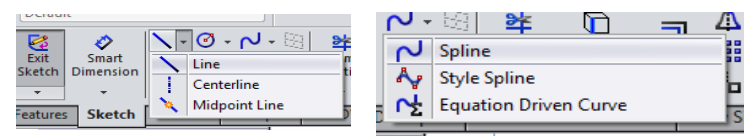

Gambar 2.8 Command Tools

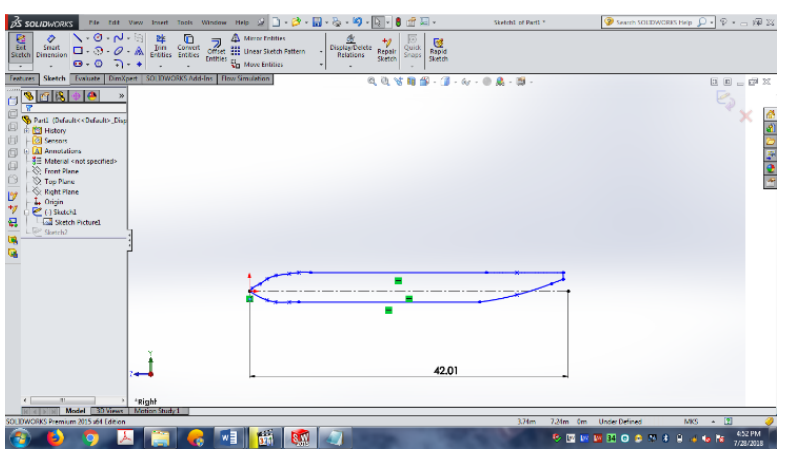

Gambar 2.9 Pembuatan untuk tampak samping

Pada proses pembuatan tampak samping menggunakan command line dan spline untuk bertujuan untuk menyatukan antara garis-garis yang ingin dibuat berdasakan refrensi Gambar. 
6. Buat model 2D untuk tampak atas

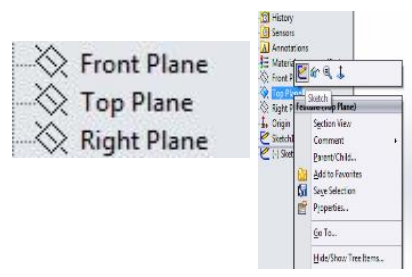

Gambar 2.10 Proses Permodelan Fuselage B737-9MAX tampak atas

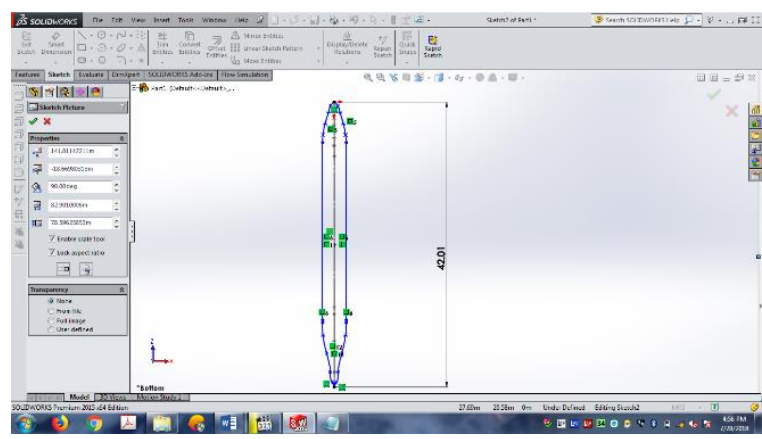

Gambar 2.11 Permodelan untuk tampak atas

Pada proses pembuatan model tampak atas sama dengan pembuatan model tampak samping tetapi untuk sketch awal menggunakan Top Plane dan menggunakan command yang sama pada Gambar 2.8.

7. Pilih Feature dan Reference Geometry untuk membuat bidang 3D

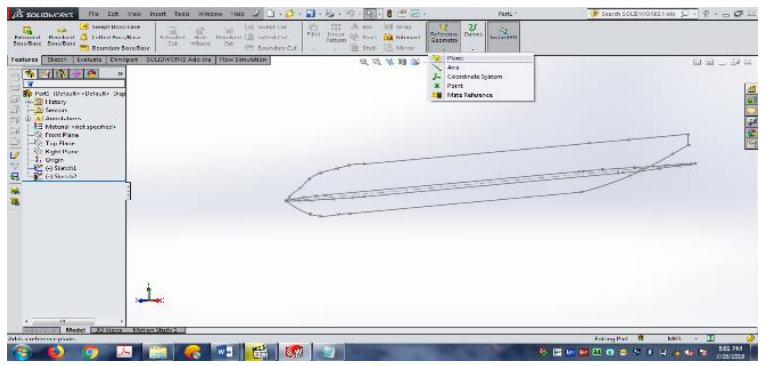

Gambar 2.12 Pemilihan bidang menggunakan plane

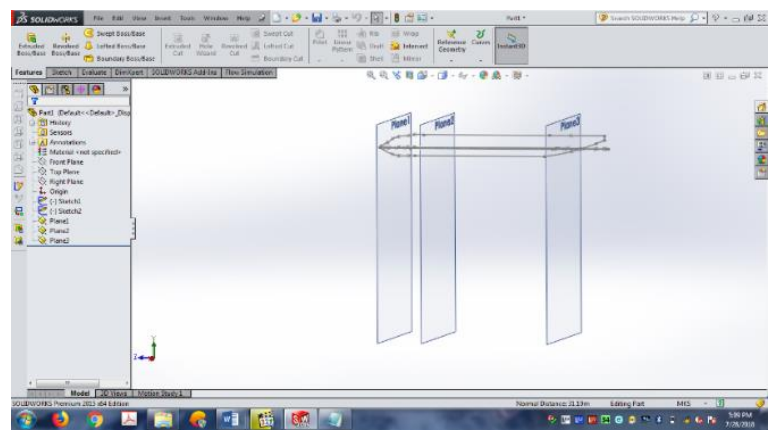

Gambar 2.13 Pembuatan bidang pada fuselage untuk tampak samping

Setelah pembuatan 2D untuk tampak samping dan tampak atas selesai selanjutnya pembuatan bidang atau plane untuk dijadikan $3 \mathrm{D}$ dan pembuatan bidang diawalin dengan tampak samping terlebih dahulu.

8. Buat lingkaran menggunakan spline

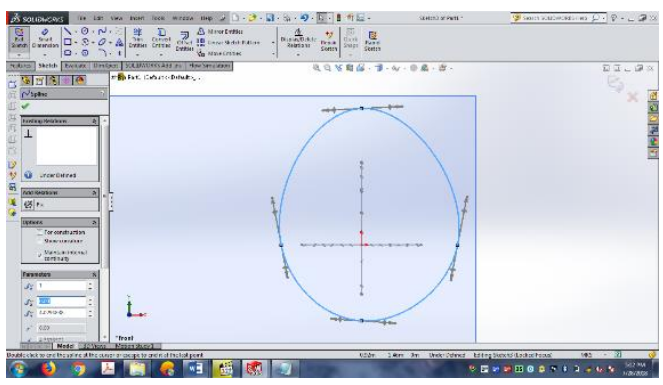

Gambar 2.14 Membuat lingkaran untuk tampak depan tahap 1

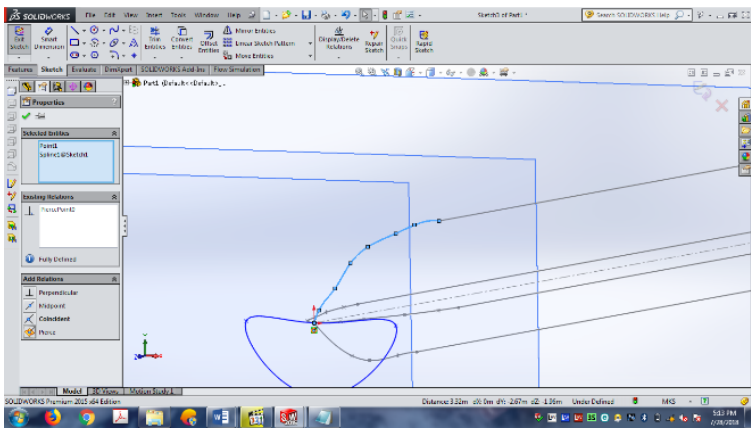

Gambar 2.15 Pembuatan lingkaran tampak depan tahap 2

Pada proses ini adalah penggabungan bidang bidang yang sudah dibuat secara oval atau lingkaran pada Gambar 2.14 dengan menyatukan lingkaran dengan garis 2D menggunakan command pierce yang ada pada Gambar 2.15. 
9. Klik features lalu klik mode Lofted boss/bass pada toolbar Features.

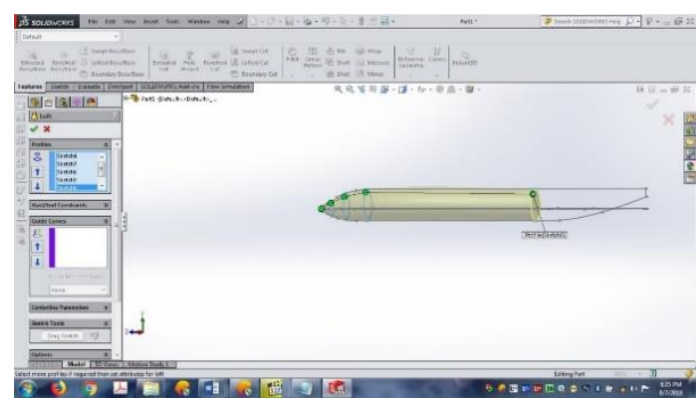

Gambar 2.16 Pembuatan 3D tahap 1

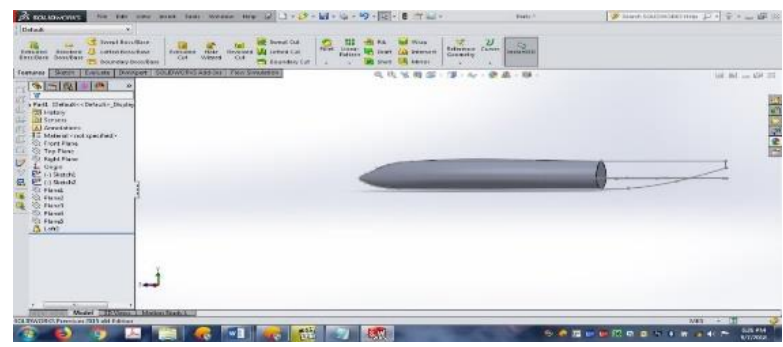

Gambar 2.17 Pembuatan 3D tahap 2

Pada proses ini adalah pengambungan lingkaran yang sudah dibuat pada Gambar 2.14 dan Gambar 2.15 untuk selanjutnya di lofted dan diklik lingkaran lingkaran tersebut pada Gambar 2.16 dan sampai akhirnya jadi seperti Gambar 2.17.

10. Hingga akhirnya seperti ini

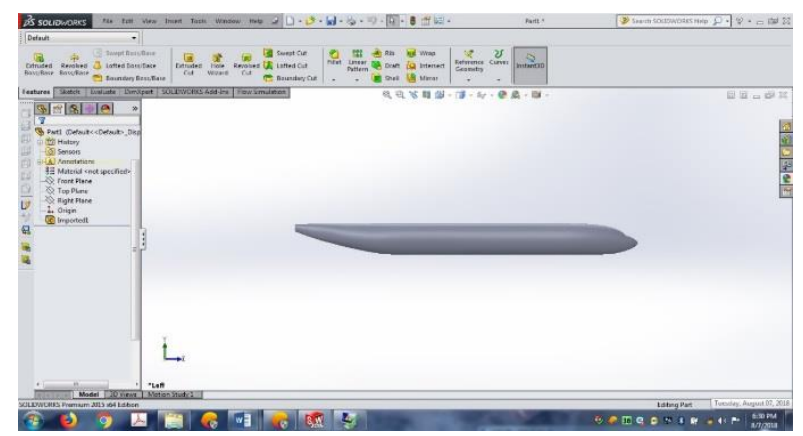

Gambar 2.18 Proses akhir permodelan

Jika sudah menjadi seperti Gambar 2.18 maka Gambar siap diuji coba dengan menggunakan flow simulation.

\section{HASIL DAN PEMBAHASAN}

\subsection{Trajectories Mach Number}

Gambar - Gambar berikut merupakan hasil flow simulation dengan variasi sudut $\left(0^{\circ}, 15^{\circ}, 30^{\circ}, 45^{\circ}\right)$. Menggunakan menu flow trajectories yang mengGambarkan kecepatan aliran udara terhadap sumbu $(X)$ di sekitar permukaan fuselage, dengan menggunakan kecepatan 0.8 Mach.

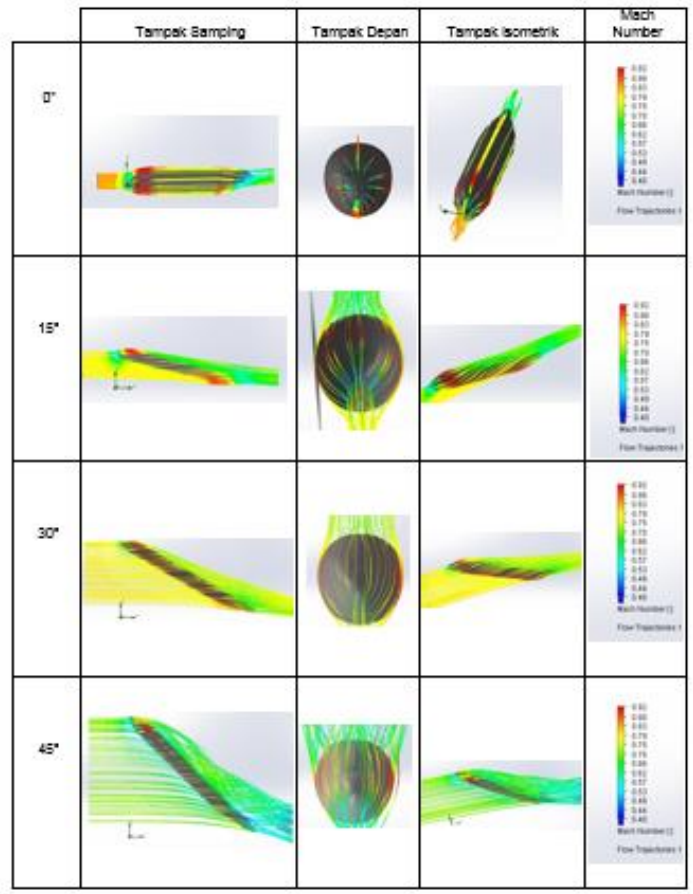

Gambar 3.1 Flow Trajectories Mach Number (X) $0^{\circ}, 15^{\circ}, 30^{\circ}, 45^{\circ}$ tampak samping, depan dan isometrik

Gambar 3.1 menunjukan aliran kecepatan udara yang mengalir disekitar fuselage yang memiliki sudut $0^{\circ}, 15^{\circ}, 30^{\circ}$, dan $45^{\circ}$. Kecepatan aliran udara yang digunakan sebesar 0.8 Mach. Gambar yang di tampilkan dalam bentuk tampak samping, depan dan isometrik agar kecepatan aliran udara dapat diamati dengan jelas.

\subsection{Surface Plot Pressure}

Gambar - Gambar berikut merupakan hasil flow simulation menggunakan menu surface plots dengan variasi sudut $\left(0^{\circ}, 15^{\circ}\right.$, $30^{\circ}$, dan $45^{\circ}$ ) Gambar yang di tampilkan dalam bentuk tampak samping, depan dan isometrik agar beban pada permukaan fuselage pesawat dapat diamati dengan jelas. Untuk beban pada permukaan model ini berdasarkan pressure yang terjadi pada seluruh permukaan area fuselage. Pada surface plots seluruh kondisi batas yang 
dipakai sama dan dialiri dengan kecepatan udara sebesar 0.8 Mach.

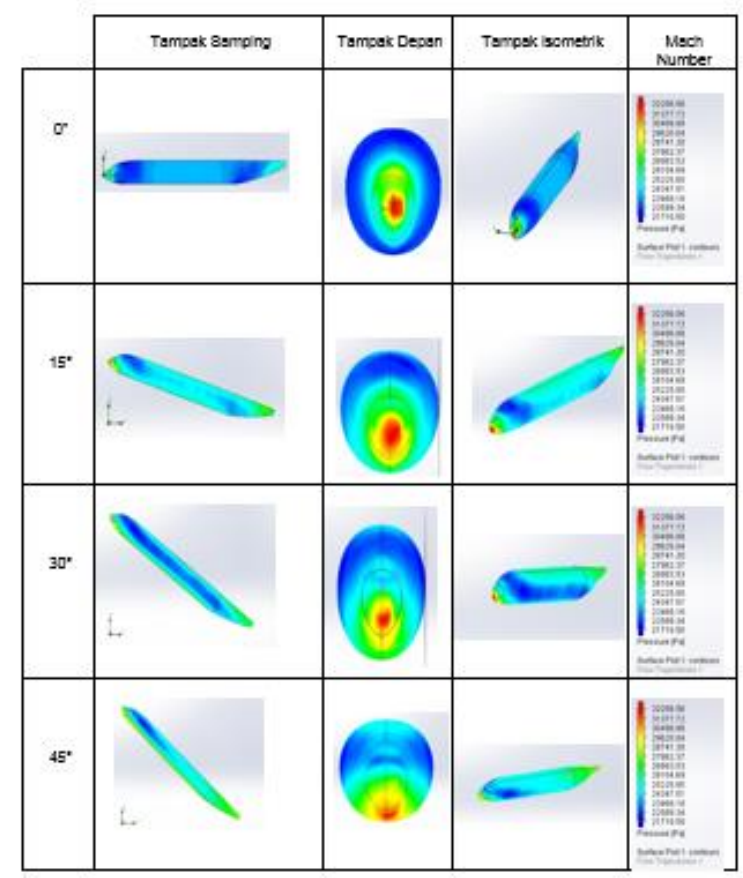

Gambar 3.2 Surface plot pressure (X) $0^{\circ}, 15^{\circ}, 30^{\circ}, 45^{\circ}$ tampak samping, depan dan isometric

Gambar 3.2 menunjukan aliran tekanan udara yang mengalir dipermukaan fuselage yang memiliki variasi sudut $0^{\circ}, 15^{\circ}$, $30^{\circ}$, dan $45^{\circ}$. Kecepatan aliran udara yang digunakan 0.8 Mach. Gambar yang di tampilkan dalam bentuk tampak samping, depan dan isometrik agar aliran udara dapat diamati dengan jelas.

\subsection{Goal Plot}

Hasil perhitungan flow simulation didapat dengan menggunakan global plot pada menu.

Tabel 3.1 Goal plot $0^{\circ}$

\begin{tabular}{|l|l|l|r|r|}
\hline Goal Name & Unit & Value & Minimum Value & $\begin{array}{l}\text { Maximum } \\
\text { Value }\end{array}$ \\
\hline GG Min Static Pressure 1 & {$[\mathrm{Pa}]$} & 21067.63902 & 21065.70221 & 21081.08291 \\
\hline GG Max Static Pressure 1 & {$[\mathrm{Pa}]$} & 37272.78671 & 37224.67704 & 37445.05512 \\
\hline GG Min Total Pressure 1 & {$[\mathrm{Pa}]$} & 21067.63902 & 21065.70221 & 21081.08291 \\
\hline GG Max Total Pressure 1 & {$[\mathrm{Pa}]$} & 46917.20885 & 46803.47126 & 47177.99687 \\
\hline GG Min Velocity 1 & {$[\mathrm{m} / \mathrm{s}]$} & 0 & 0 & 0 \\
\hline GG Max Velocity 1 & {$[\mathrm{m} / \mathrm{s}]$} & 255.2285587 & 254.6777809 & 255.4694952 \\
\hline
\end{tabular}

Tabel 3.2 Goal plot $15^{\circ}$

\begin{tabular}{|l|l|l|r|l|}
\hline & Unit & Value & $\begin{array}{l}\text { Minimum } \\
\text { Value }\end{array}$ & $\begin{array}{l}\text { Maximum } \\
\text { Value }\end{array}$ \\
\hline GG Min Static Pressure 1 & {$[\mathrm{Pa}]$} & 18948.63099 & 18947.66842 & 18987.69207 \\
\hline GG Max Static Pressure 1 & {$[\mathrm{Pa}]$} & 32620.51572 & 32620.33893 & 32624.91704 \\
\hline GG Min Total Pressure 1 & {$[\mathrm{Pa}]$} & 18948.63099 & 18947.66842 & 18987.69207 \\
\hline GG Max Total Pressure 1 & {$[\mathrm{Pa}]$} & 38823.31771 & 38813.42929 & 38824.31768 \\
\hline GG Min Velocity 1 & {$[\mathrm{m} / \mathrm{s}]$} & 0 & 0 & 0 \\
\hline GG Max Velocity 1 & {$[\mathrm{m} / \mathrm{s}]$} & 270.0190431 & 269.6659686 & 270.022426 \\
\hline
\end{tabular}

Tabel 3.3 Goal plot $30^{\circ}$

\begin{tabular}{|l|l|l|l|l|}
\hline Goal Name & Unit & Value & $\begin{array}{l}\text { Minimum } \\
\text { Value }\end{array}$ & $\begin{array}{l}\text { Maximum } \\
\text { Value }\end{array}$ \\
\hline GG Min Static Pressure 1 & {$[\mathrm{Pa}]$} & 15496.20486 & 15334.56733 & 15501.56355 \\
\hline GG Max Static Pressure 1 & {$[\mathrm{Pa}]$} & 36320.94659 & 36293.14459 & 36320.94659 \\
\hline GG Min Total Pressure 1 & {$[\mathrm{Pa}]$} & 15496.35954 & 15334.72201 & 15501.71823 \\
\hline GG Max Total Pressure 1 & {$[\mathrm{Pa}]$} & 44995.98181 & 44975.19714 & 45015.86362 \\
\hline GG Min Velocity 1 & {$[\mathrm{m} / \mathrm{s}]$} & 0 & 0 & 0 \\
\hline GG Max Velocity 1 & {$[\mathrm{m} / \mathrm{s}]$} & 296.4926766 & 296.4311118 & 296.7865746 \\
\hline
\end{tabular}

Tabel 3.4 Goal plot $45^{\circ}$

\begin{tabular}{|l|l|l|r|r|}
\hline & Unit & Value & $\begin{array}{l}\text { Minimum } \\
\text { Value }\end{array}$ & $\begin{array}{l}\text { Maximum } \\
\text { Value }\end{array}$ \\
\hline G G Min Static Pressure 1 & {$[\mathrm{Pa}]$} & 11462.06289 & 11451.99424 & 11501.07691 \\
\hline GG Max Static Pressure 1 & {$[\mathrm{Pa}]$} & 39457.77676 & 39436.03468 & 39457.80374 \\
\hline GG Min Total Pressure 1 & {$[\mathrm{Pa}]$} & 11462.33043 & 11452.26179 & 11501.34446 \\
\hline GG Max Total Pressure 1 & {$[\mathrm{Pa}]$} & 47010.25796 & 46962.21443 & 47014.48371 \\
\hline GG Min Velocity 1 & {$[\mathrm{m} / \mathrm{s}]$} & 0 & 0 & 0 \\
\hline GG Max Velocity 1 & {$[\mathrm{m} / \mathrm{s}]$} & 333.9202678 & 333.9202678 & 334.2849331 \\
\hline
\end{tabular}

Tabel 3.1, Tabel 3.2, Tabel 3.3, dan Tabel 3.4 menjelaskan tentang hasil Goal Plot pada variasi sudut $\left(0^{\circ}, 15^{\circ}, 30^{\circ}\right.$, dan $45^{\circ}$ ). Nilai pressure tertinggi pada sudut $45^{\circ}$ yaitu sebesar $39457 \mathrm{~Pa}$ sedangkan untuk pressure terendah pada sudut $15^{\circ}$ yaitu sebesar $32624 \mathrm{~Pa}$, dan untuk kecepatan tertinggi pada sudut $45^{\circ}$ yaitu sebesar 334 $\mathrm{m} / \mathrm{s}$ dan kecepatan terendah pada sudut $0^{\circ}$ yaitu sebesar $255 \mathrm{~m} / \mathrm{s}$.

\subsection{Perbandingan Grafik}

Dalam penulisan tugas akhir ini penulis membandingkan antara kecepatan dan tekanan dengan menggunakan kecepatan sebesar 0.8 Mach dan varisi sudut $0^{\circ}, 15^{\circ}$, $30^{\circ}, 45^{\circ}$ sebagai berikut :

\subsubsection{Perbandingan Grafik Sudut $0^{\circ}$}
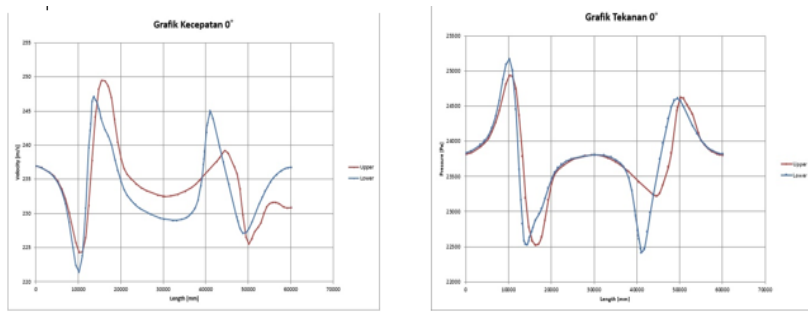

Gambar 3.3 Grafik Sudut $0^{\circ}$ 
Dapat dilihat pada grafik sudut $0^{\circ}$ perbedaan tekanan dan kecepatan upper dan lower bahwa kecepatan dan tekanan berbanding terbalik terhadap sudut yang diberikan, pada saat kecepatan dari sumbu $X$ atau arah aliran $237 \mathrm{~m} / \mathrm{s}$ mengalami penurunan sampai $224 \mathrm{~m} / \mathrm{s}$ untuk jarak $10000 \mathrm{~mm}$ untuk bagian upper, sedangkan untuk bagian lower juga mengalami penurunan kecepatan sebesar $221 \mathrm{~m} / \mathrm{s}$ dari kecepatan awal $237 \mathrm{~m} / \mathrm{s}$ sampai $10000 \mathrm{~mm}$ hal ini terjadi karena adanya benturan aliran terhadap fuselage dan untuk tekanan mengalami kenaikkan, lalu pada 10000 mm kecepatan mengalami kenaikkan yang sangat signifikan dari $225 \mathrm{~m} / \mathrm{s}$ sampai 247 $\mathrm{m} / \mathrm{s}$ untuk bagian upper sedangkan lower dari $222 \mathrm{~m} / \mathrm{s}$ sampai $244 \mathrm{~m} / \mathrm{s}$.

Pada ujung fuselage $10000 \mathrm{~mm}$ sampai jarak $15000 \mathrm{~mm}$ terjadi perubahan penurunan tekanan yang sangat signifikan, jarak $20000 \mathrm{~mm}$ sampai $40000 \mathrm{~mm}$ mengalami penurunan dan kenaikkan yang tidak terlalu signifikan dan pada jarak 40000 $\mathrm{mm}$ sampai $50000 \mathrm{~mm}$ terdapat perbedaan tekanan yang cukup signifkan, hal ini terjadi dikarenakan adanya perbedaan bentuk fuselage untuk bagian upper dan lower.

\subsubsection{Perbandingan Grafik Sudut $15^{\circ}$}
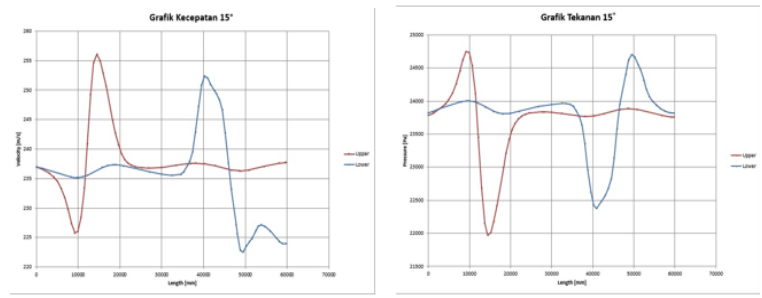

Gambar 3.4 Grafik Sudut $15^{\circ}$

Grafik perbandingan kecepatan dan tekanan pada sudut $15^{\circ}$ untuk jarak 0 sampai $10000 \mathrm{~mm}$ mengalami penurunan kecepatan untuk dibagian upper dari $237 \mathrm{~m} / \mathrm{s}$ menjadi $227 \mathrm{~m} / \mathrm{s}$ hal ini terjadi karena perubahan sudut akan bepengaruh terhadap aliran untuk bagian lower tidak ada perubahan yang signifikan karena aliran terus mengalir dan menyentuh bagian yang berbeda dengan upper dan tekanan untuk bagian upper pun mejadi naik karena adanya tekanan sedangkan untuk lower juga mengalami kenaikkan tapi tidak terlalu signifkan, untuk jarak $10000 \mathrm{~mm}$ sampai $15000 \mathrm{~mm}$ mengalami kenaikkan kembali dari $227 \mathrm{~m} / \mathrm{s}$ sampai $256 \mathrm{~m} / \mathrm{s}$ untuk bagian upper sedangkan pada bagian lower tidak ada perubahan dari awal adanya kecepatan tersebut.

Sedangkan untuk nilai tekanan pada bagian upper dan lower memiliki perbedaan yang sangat signifikan di setiap jaraknya, dimana pada bagian upper tekanan terbesar pada jarak $10000 \mathrm{~mm}$ dan tekanan terendah pada jarak $15000 \mathrm{~mm}$. Pada bagian lower tekanan terbesar pada jarak $50000 \mathrm{~mm}$ dan tekanan terendah pada jarak $40000 \mathrm{~mm}$. Hal ini terjadi adanya perubahan sudut dari fuselage yang sangat berpengaruh pada perubahan nilai tekanan dan kecepatan

\subsubsection{Perbandingan Grafik Sudut $30^{\circ}$}

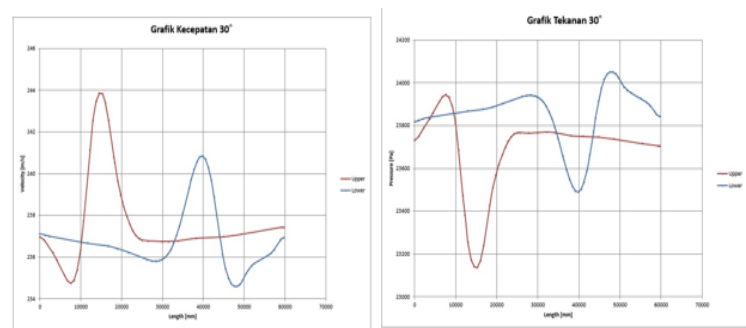

Gambar 3.5 Grafik Sudut $30^{\circ}$

Sedangkan untuk sudut $30^{\circ}$ kecepatan dari 0 sampai 10000 untuk bagian upperjuga mengalami penurunan dari $237 \mathrm{~m} / \mathrm{s}$ sampai dengan $233 \mathrm{~m} / \mathrm{s}$ dan untuk lower tidak mengalami perubahan yang signifikan beda dengan pada sudut $15^{\circ}$ hal ini terjadi karena aliran kecepatan yang mengalir tidak terlalu parah dibandingkan dengan aliran kecepatan pada sudut $0^{\circ}$ dan $15^{\circ}$, tetapi pada saat jarak $10000 \mathrm{~mm}$ sampai dengan $15000 \mathrm{~mm}$ kecepatan aliran meningkat sangat drastis untuk bagian upper dari 233 $\mathrm{m} / \mathrm{s}$ sampai dengan $244 \mathrm{~m} / \mathrm{s}$.

Sedangkan itu pada jarak $15000 \mathrm{~mm}$ sampai dengan $20000 \mathrm{~mm}$ bagian upper mengalami penurunan kecepatan dari 244 $\mathrm{m} / \mathrm{s}$ sampai $237 \mathrm{~m} / \mathrm{s}$ kembali pada awal kecepatan tetapi ketika jarak $20000 \mathrm{~mm}$ sampai $30000 \mathrm{~mm}$ untuk bagian lower mengalami kenaikkan dari $237 \mathrm{~m} / \mathrm{s}$ sampai dengan $241 \mathrm{~m} / \mathrm{s}$ hal ini terjadi karena struktur 
fuselage yang berbeda dan juga dipengaruhi oleh sudut, dan untuk tekanan berbanding terbalik terhadap kecepatannya.

\subsubsection{Perbandingan Grafik Sudut $45^{\circ}$}

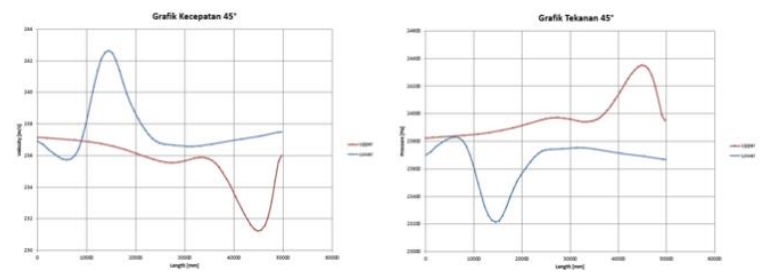

Gambar 3.6 Grafik Sudut $45^{\circ}$

Pada grafik diatas dapat dilihat bahwa ada perubahan kecepatan dan tekanan dari jarak 0 sampai $10000 \mathrm{~mm}$ untuk lower mengalami penurunan kecepatan dari 237 $\mathrm{m} / \mathrm{s}$ sampai $235 \mathrm{~m} / \mathrm{s}$ hal ini terjadi karena bagian lower terlebih dahulu yang mengenai aliran udara sedangkan untuk upper tidak terlalu signifkan untuk berubahan kecepatan dan tekannya tetapi untuk tekanan lower mengalami penurunan, sedangkan untuk jarak $10000 \mathrm{~mm}$ sampai $15000 \mathrm{~mm}$ untuk bagian lower mengalami peningkatan hal ini terjadi karena aliran yang terkena oleh fuselage terlebih dahulu adalah bagian lower

Tetapi untuk bagian upper tidak terpengaruh aliran kecepatan yang lebih banyak dari pada lower tetapi pada jarak $33000 \mathrm{~m} / \mathrm{s}$ sampai $45000 \mathrm{~m} / \mathrm{s}$ aliran kecepatan upper mengalami penurunan dari $236 \mathrm{~m} / \mathrm{s}$ sampai $231 \mathrm{~m} / \mathrm{s}$ lalu mengalami kenaikkan kembali menjadi $236 \mathrm{~m} / \mathrm{s}$ sedangkan untuk lower tetap sama hal ini terjadi karena aliran pada fuselage sudah tidak berpengaruh lagi, dan untuk tekanannya berbanding terbalik terhadapat kecepatannya.

\section{KESIMPULAN}

Berdasarkan hasil yang diperoleh pada pembahasan, maka dapat diambil beberapa kesimpulan sebagai berikut:

1. Pada fuselage Boeing 737 MAX 9 ini telah diketahui untuk kecepatan 0.8 Mach dengan variasi sudut $0^{\circ}, 15^{\circ}, 30^{\circ}$, $45^{\circ}$. Dengan demikian untuk kecepatan $0^{\circ}$ didapat $254 \mathrm{~m} / \mathrm{s}-255 \mathrm{~m} / \mathrm{s}$, sedangkan tekanannya $46803 \mathrm{~Pa}-47177 \mathrm{~Pa}$, untuk $15^{\circ}$ didapat kecepatan $269 \mathrm{~m} / \mathrm{s}-270 \mathrm{~m} / \mathrm{s}$ dengan tekanannya $38813 \mathrm{~Pa}-38824$ $\mathrm{Pa}$, sedangkan untuk $30^{\circ}$ didapat kecepatan $296 \mathrm{~m} / \mathrm{s}$ - $296 \mathrm{~m} / \mathrm{s}$ dan tekanannya $44975 \mathrm{~Pa}-45015 \mathrm{~Pa}$, dan untuk $45^{\circ}$ kecepatannya $333 \mathrm{~m} / \mathrm{s}-334$ $\mathrm{m} / \mathrm{s}$, dan tekanannya $46962 \mathrm{~Pa}-47014$ $\mathrm{Pa}$.

2. Dengan memperhatikan hasil visualisasi aliran yang ada bahwa setiap sudut yang berbeda mengalami perubahan aliran kecepatan dan aliran tekanan berbeda, tetapi untuk aliran kecepatan dan aliran tekanan berbanding terbalik terhadap aliran tersebut.

3. Dalam pengujian ini dapat dilihat bahwa sudut $0^{\circ}, 15^{\circ}, 30^{\circ}, 45^{\circ}$ mengalami berbedaan tekanan dan kecepatan, untuk sudut $0^{\circ}, 15^{\circ}$ masih bisa dibilang normal untuk sebuah pesawat, sedangkan pada sudut $30^{\circ}$ dan $45^{\circ}$ sudut tidak normal untuk sebuah sudut pesawat karena aliran pada sudut tersebut sudah diatas rata-rata normal atau banyak mengalami turbulensi.

\section{DAFTAR PUSTAKA}

1. Federal Aviation Administration. 2012. Aviation Maintance Technician Handbook-airframe. USA : Department of Transportation https://www.faa.gov/ regulations_policies/handbooks_manual s/aviation/phak/media/05_phak_ch3.pdf diakses pada tanggal 30 Juni 2018

2. Boeing Commercial Airplanes, 2018, Configuration Specification Boeing 737MAX 9, USA

3. Boeing 737-MAX 9 Efficiancy, Reliability, Passenger appeal https://www.boeing. com/commercial/737max/, diakses pada 29 Juni 2018

4. Anderson, Jhon D, Jr. 1995. Computational Fluida Dynamic $\left(2{ }^{\text {nd }} e d\right)$. New York: McGraw 